\title{
Influence analysis of climate data time-step on the accuracy of HAM simulation
}

\author{
Peter Juras ${ }^{1, *}$, and Daniela Jurasova ${ }^{1}$ \\ ${ }^{1}$ Department of Building Engineering and Urban Planning, Faculty of Civil Engineering, University \\ of Zilina, Univerzitna 8215/1, 01026 Zilina, Slovakia
}

\begin{abstract}
Scientific research in the area of building simulations has a great potential and it is continuously developing and advancing. Computer simulations are helpful in many areas of Civil Engineering, such as energy demand, moisture transport, thermal comfort, ventilation etc. Climate data measured by experimental weather station are analyzed in this article. Weather station is located within the University campus and data recorded with a short are used in a non-steady heat-air-moisture simulation. Climate parameters differences caused by the various averaging periods are shown. This differences are also analyzed in term of outdoor surface temperatures calculated with WUFI Pro simulation software.
\end{abstract}

\section{Introduction}

Scientific research in the area of solar radiation and building physics brings new and sophisticated numerical and simulative models. These models require more detailed material parameters and boundary conditions. For heat-air-moisture simulation, both mentioned points are crucial, namely the water transport in porous materials [1] and also the outdoor climate, e. g. wind-driven rain amount [2]. That is why the material database has to be regularly updated and also outdoor boundary conditions - especially microclimatic characteristics around the building - have to be as accurate as possible.

The Slovak Hydrometeorological Institute (SHMI), the national weather service, has built a network of weather stations, which usually measure air temperatures, rainfall, wind velocity and wind direction and many other meteorological elements. In building simulation there are needed measurements of special meteorological variables, which are measured by specialized meteorological stations. Global and diffuse solar radiation are measured only at several stations of the SHMI. The closest station providing diffuse solar radiation measurement is hundreds of kilometers away (Bratislava, Poprad, totally only six in Slovakia) from the Research laboratories belongings to the University of Zilina. With global solar radiation the situation looks better, but as it will be shown in this article it is not enough. Typical meteorological station measure only the horizontal rainfall, but for experiments conducted in Civil Engineering is wind-driven rain more important [2]. Own weather station was installed to obtain more specialized climate parameters because of deficient special data needed from the national weather service. Department has its own

\footnotetext{
* Corresponding author: peter.juras@fstav.uniza.sk
} 
weather station since 2013 [3] but since 2017 there is the second one in operation - an upgraded version equipped with additional measured parameters: long-wave radiation, UV and diffuse solar radiation. First results of simulations using measured local data are presented in this study.

\section{Weather station description}

Location of new weather station is specified in Table 1. This new automatic weather station (since 2017) is used for whole experimental research conducted by the department (Fig. 1), such as façade research [4], wooden wall research [5] or research of windows for low energy houses [6]. For all conducted research tasks, a precise and high resolution monitoring of climate parameters is very important.

Table 1. Coordinates of the new weather station.

\begin{tabular}{|c|c|c|}
\hline Longitude & Latitude & Altitude A.S.L. [m] \\
\hline $18^{\circ} 45^{\prime} 23.6^{\prime \prime}$ & $49^{\circ} 12^{\prime} 8.26^{\prime \prime}$ & 386,44 \\
\hline
\end{tabular}

This weather station has been in operation since 2017 with some interruptions caused by the sensor exchange. The weather station is equipped with an ultrasonic anemometer, thermometer, relative humidity sensors, barometer, tipping bucket for rainfall, pyrgeometer, UV sensor and also with two pyranometers. One pyranometer is equipped with a shading ring to measure diffuse radiation. Measured quantities are summarized in Table 2. The aim of this study was to show influence of known diffuse irradiance on surface temperature and relative humidity simulations at the exterior side of the experimental wooden-framed wall.

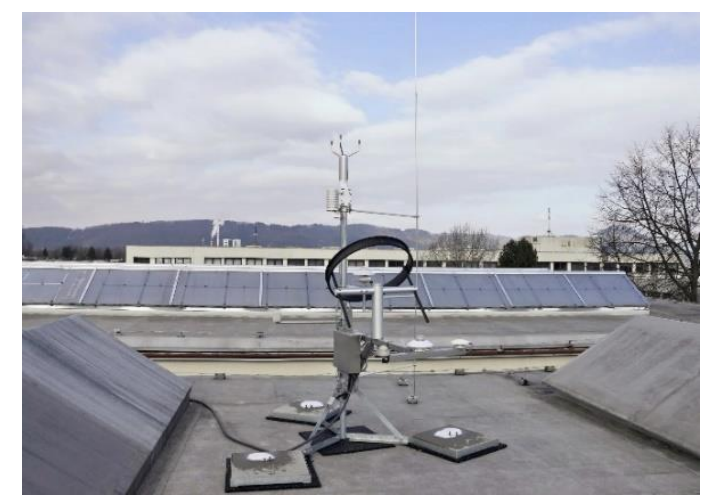

Fig. 1. Detailed view at new weather station located on the roof of laboratory [5] including a shading ring for diffuse solar radiation measurement.

Table 2. Meteorological quantities measured by the weather station.

\begin{tabular}{|c|c|}
\hline Measured quantity & Unit \\
\hline Air temperature & {$\left[{ }^{\circ} \mathrm{C}\right]$} \\
\hline Relative humidity & {$[\%]$} \\
\hline Barometric air pressure & {$[\mathrm{hPa}]$} \\
\hline Global solar radiation & {$\left[\mathrm{W} / \mathrm{m}^{2}\right]$} \\
\hline Diffuse solar radiation & {$\left[\mathrm{W} / \mathrm{m}^{2}\right]$} \\
\hline Long-wave radiation & {$\left[\mathrm{W} / \mathrm{m}^{2}\right]$} \\
\hline UV radiation & {$\left[\mathrm{mW} / \mathrm{cm}^{2}\right]$} \\
\hline Wind velocity & {$[\mathrm{m} / \mathrm{s}]$} \\
\hline Wind direction & {$\left[{ }^{\circ}\right]$} \\
\hline Rainfall & {$\left[\mathrm{mm} / \mathrm{m}^{2}\right]$} \\
\hline \multicolumn{2}{|c}{} \\
\hline
\end{tabular}




\section{Measured climate data analysis}

Three days of April (26 - 28 April 2018) were used for a simulation. Measured courses of quantities are shown in Fig. 2. Not all measured quantities are represented, only the selected ones. These three days were chosen because of including one cloudy day, one sunny day and one sunny day with clouds.

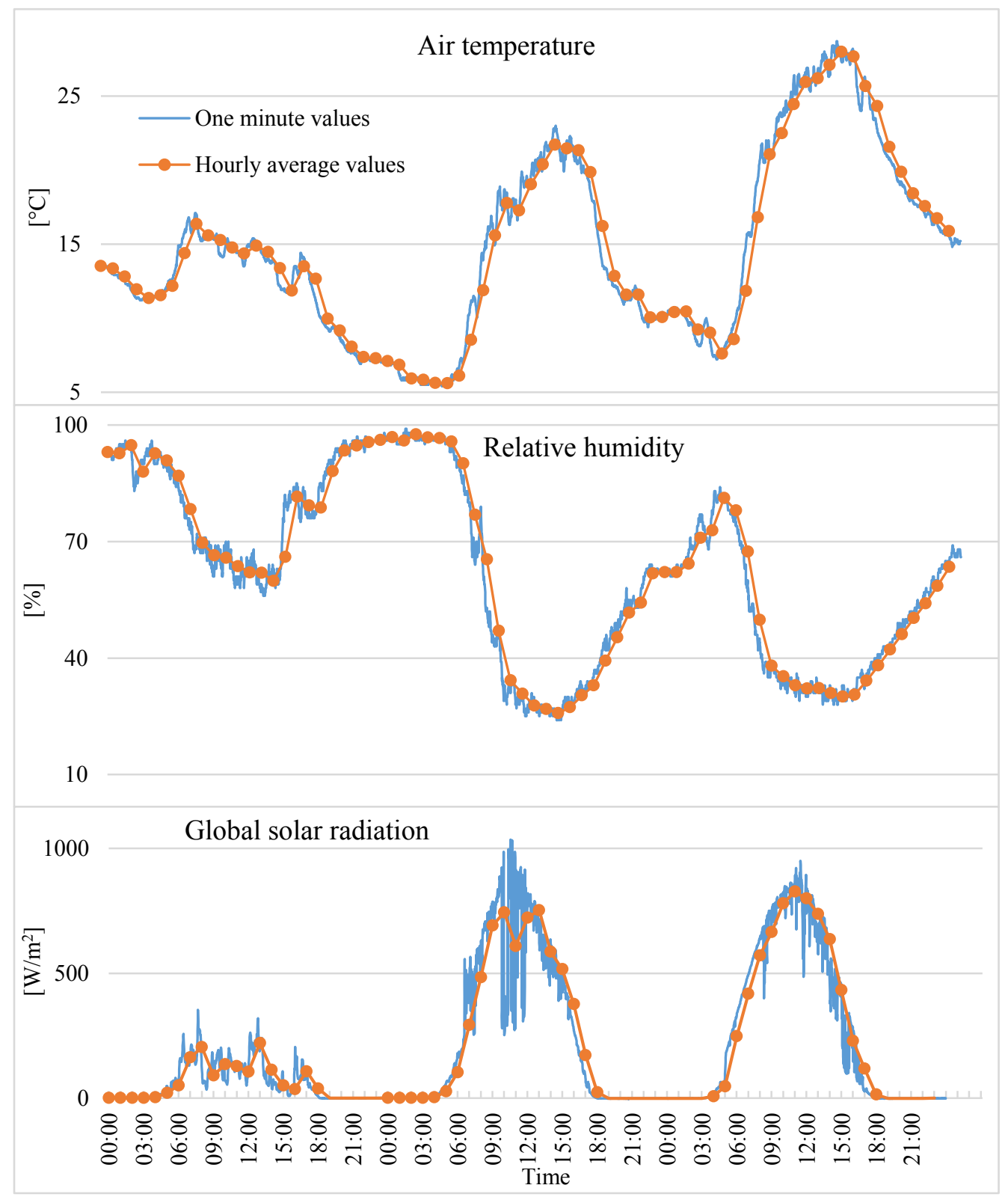

Fig. 2. Courses of air temperature, relative humidity and global solar radiation for the date period $26-$ 28 April 2018. Values are shown in one-minute interval and hourly averages. 
There are significant differences among the courses, both in the shape of the courses sometimes and also in the values. To have a closer look at the courses was chosen $27^{\text {th }}$ April and time from 9:00 to 14:00. Courses of air temperature and global solar radiation, which are directly connected are presented in Fig. 3. The longer the averaged period, the flatter the course and it does not represent the real course of the quantities well.

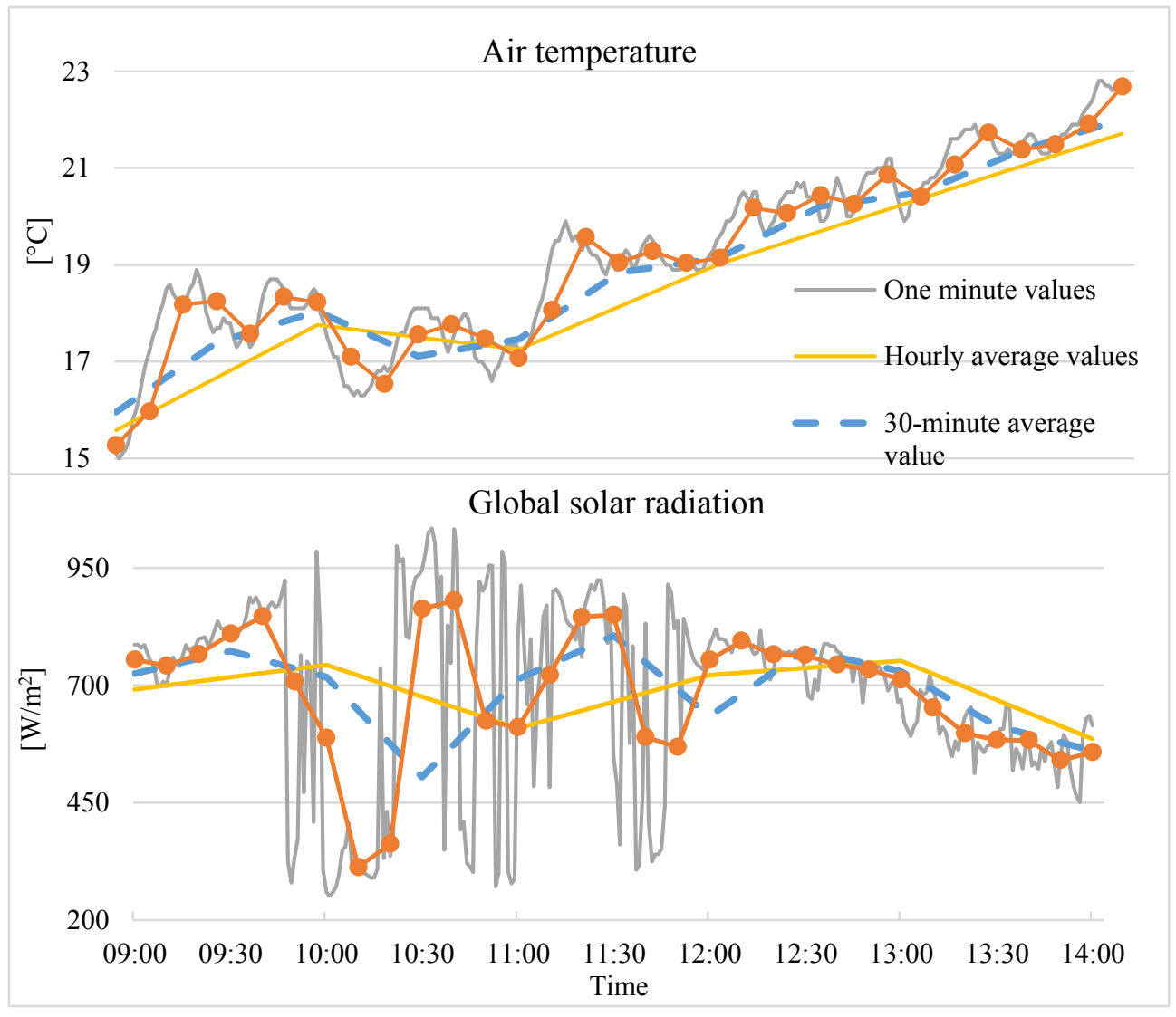

Fig. 3. Courses of air temperature and global solar radiation for 27 April and time period from 9:00 to 14:00.

\section{Heat-air-moisture simulation}

Software used in this paper is WUFI Pro in version 5.1. WUFI is a software which allows a realistic calculation of the transient coupled one- and two-dimensional heat and moisture transport described by Kunzel [7] in multi-layer building components exposed to the real climate. It is based on the newest findings regarding vapor diffusion and liquid transport in building materials and it has been validated by the detailed comparison with measurements obtained in the laboratory and on the Institute for Building Physics outdoor testing field.

The software handles with heat and moisture transport in one dimension. Data measured by the weather station enter the software as outdoor boundary conditions. Material properties of the wall tested in simulation were taken from the software library.

Simulated wall composition was taken from the experimental wooden wall research and it is described in Table 3. 
Table 3 Detailed construction of the reference wall (from outside).

\begin{tabular}{|c|c|c|c|c|}
\hline $\begin{array}{c}\text { Wooden-framed } \\
\text { wall }\end{array}$ & $\begin{array}{c}\text { External acrylic } \\
\text { coating }\end{array}$ & $\begin{array}{c}\text { Woodfiber } \\
\text { MDF Board }\end{array}$ & $\begin{array}{c}\text { Mineral wool } \\
\text { insulation }\end{array}$ & $\begin{array}{c}\text { Vapor barrier } \\
\text { OSB Board }\end{array}$ \\
\hline Thickness [mm] & 4 & 100 & 220 & 12 \\
\hline
\end{tabular}

The three days were selected because of cloudy weather on first day and sunny in two following days (not perfectly clear but with some clouds passing). This will show the influence of diffuse radiation on the temperature of exterior surface of the coating. Second investigated parameter was the resolution of measured data. The weather station works with a recording interval of one minute and for the simulation hourly and 30-minutes averages were used (Fig. 2).

For the simulation data set were used measured values: air temperature, relative humidity, barometric pressure, wind velocity and direction and global and diffuse solar radiation. Basic time step in WUFI and most simulation software is one hour. Software WUFI itself has a possibility to use shorter time step, but the function is not well implemented. On the other hand, for the CFD software with wind-flow etc. a time step as short as possible is required. Calculated values for outdoor surface temperatures are shown in Fig. 4.

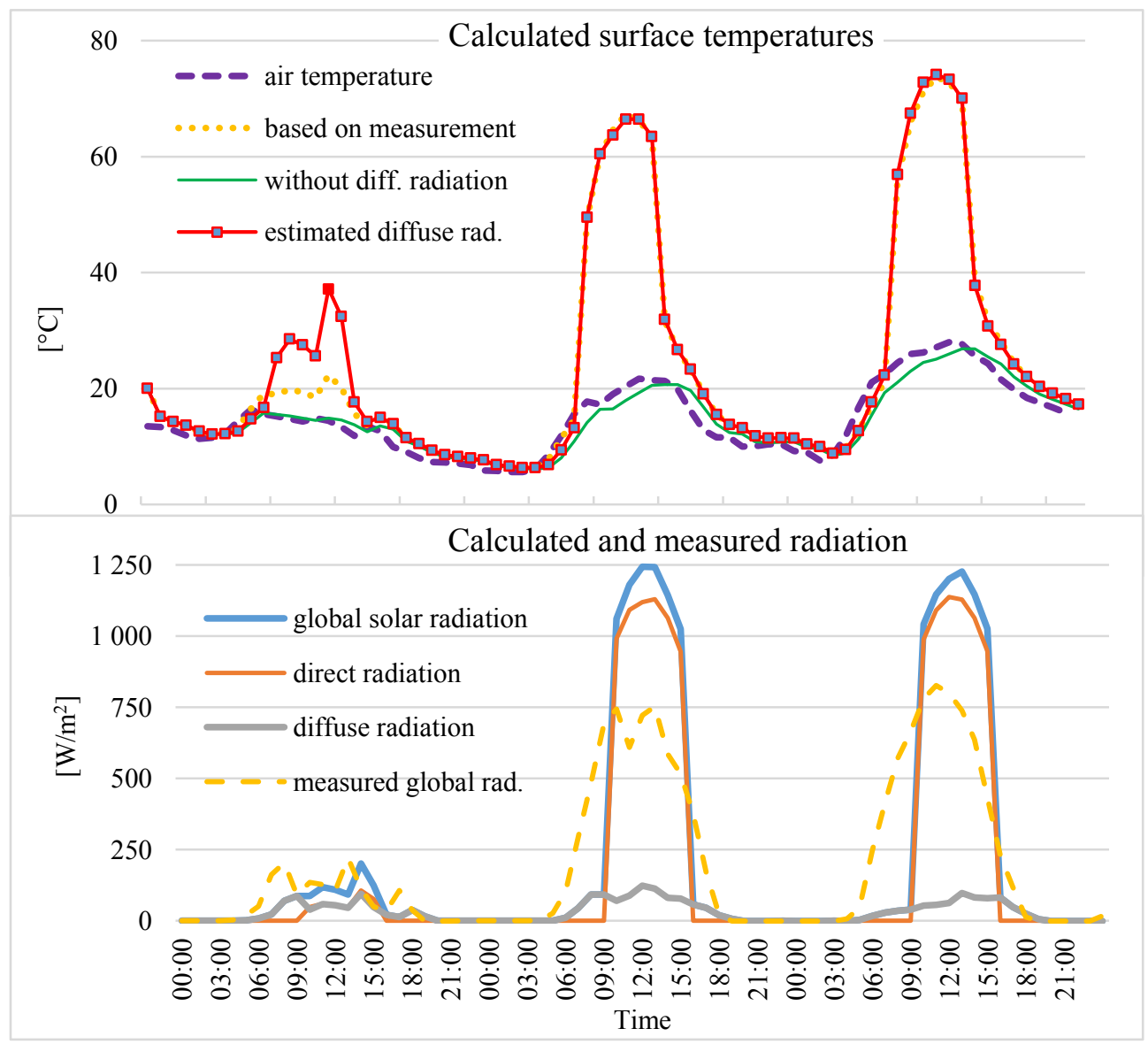

Fig. 4. Results of calculation: courses of surface temperatures for different boundary conditions. Lower graph represents boundary condition interpreted in WUFI for the south oriented wall with zero inclination (vertical wall). Measured course value is measured on the horizontal plane. 
There are three calculated courses. First is obtained by calculation with measured (averaged hourly values), the other course is without diffuse radiation and the last one is with estimated diffuse radiation as $25 \%$ of global radiation. In the lower graph there are presented calculated radiations on the wall by the program according to the chosen orientation and inclination from the vertical plane (south, zero inclination).

Reference file for data set for WUFI is *.wac file, which have in the file header possibility for time step definition, but the program cannot interpret shorter time step in correct way, because program calculate the duration of the radiation according to the latitude, longitude, date and wall orientation and inclination. This can be clearly seen for 30 minutes values (Fig. 5) and in original one minute values (Fig. 6). The 30-minute calculation is not usable at all. One-minute calculation is better in shape and values, but if we take a closer look, the course is created by the values with big differences between the following values. This is probably caused by the previously mentioned interpretation of duration of radiation.

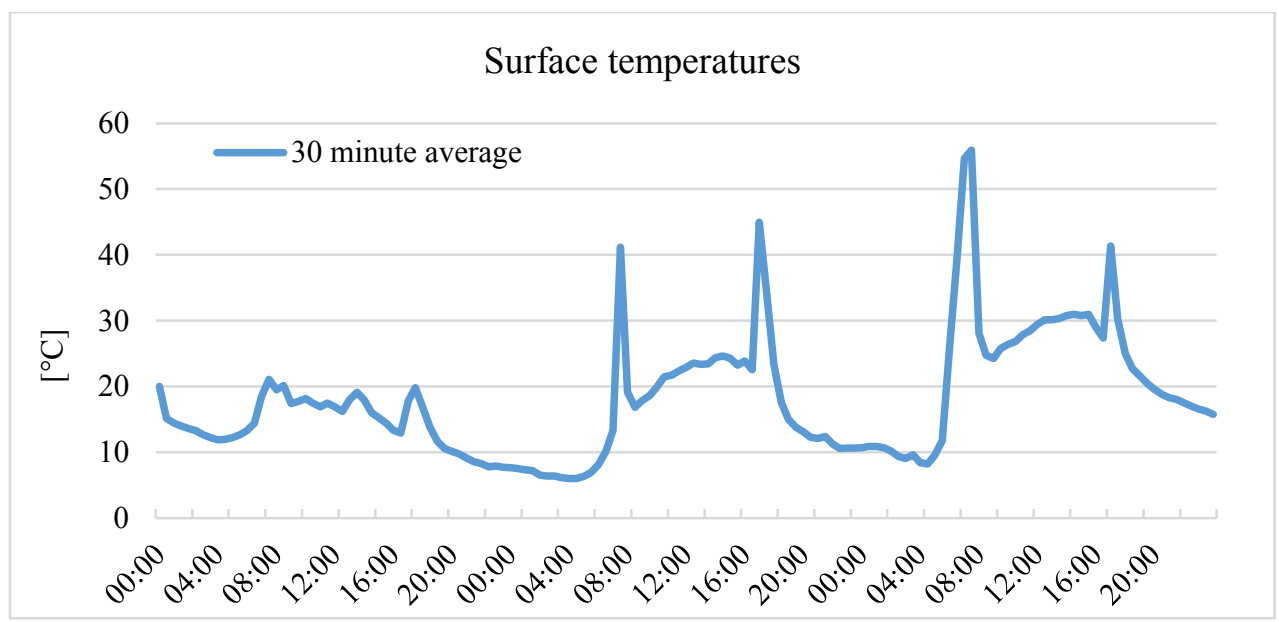

Fig. 5. Results of calculation: course of surface temperature with boundary condition created as 30minutes averages.

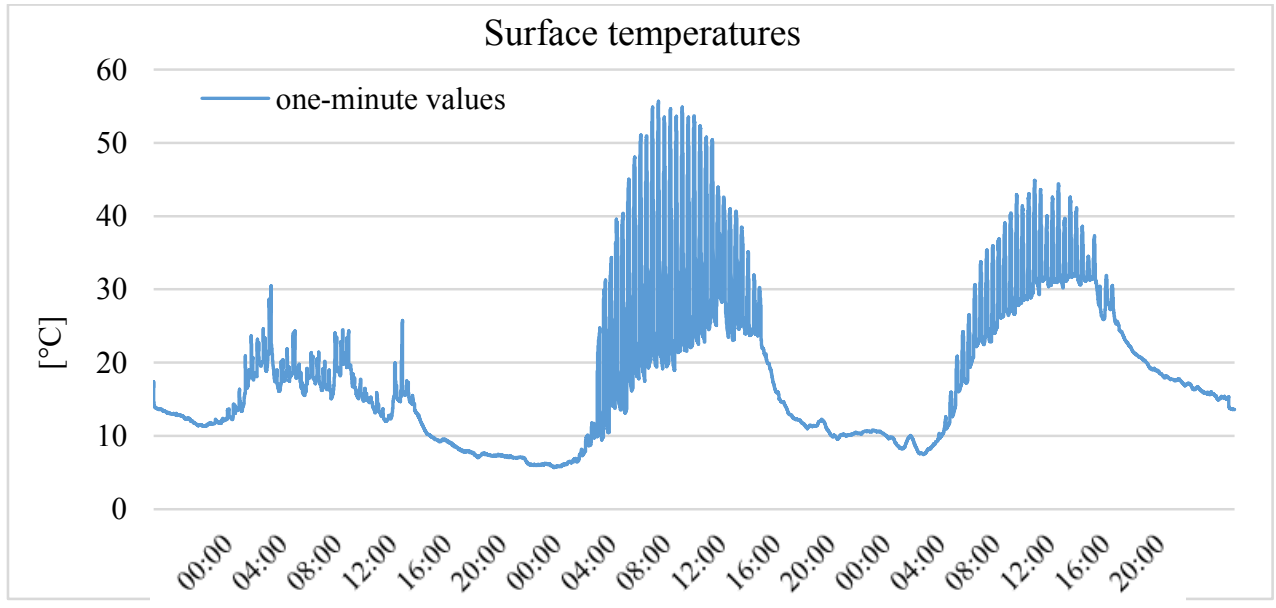

Fig. 6. Results of calculation: course of surface temperature with boundary condition created as the one-minute average (recording period). 


\section{Results and discussion}

Results of calculation averages from different time duration (10 minutes, 30 minutes and 1 hour) of boundary conditions / climate parameters are shown in Figures 2 and 3. It is shown that the larger the time interval, the flatter the course and the fluctuations cannot be interpreted in calculation correctly. This could not be an issue in HAM simulation, because moisture transport is slow. But for some simulation this could create error, e.g. if we need to observe the highest temperature on the surface, even for short time period.

Results of calculation using the averaged climate parameters as boundary conditions are presented in Fig. 4-6. As mentioned before, unfortunately the WUFI *.wac files are not working properly, respectively the results are not correct if shorter than one hour values are used. Manual and WUFI wiki recommends in this cases *.kli files, but there is limited amount of climate parameters and diffuse radiation is missing.

The influence of diffuse radiation is shown in simulation with hourly averages (Fig. 4). Based on the previous measurement, the $25 \%$ estimation from the global radiation showed a very good match during the sunny days, where the diffuse component is small. During the cloudy day, the diffuse component is higher so the results of calculation are not real, surface temperatures are higher up to $15^{\circ} \mathrm{C}$, instead of $20^{\circ} \mathrm{C}$ they are about $35^{\circ} \mathrm{C}$. If there is only global radiation available, the results of surface temperatures as the outcome of the calculation are about the outdoor air. The software has the radiation amount, but it is not able to know how is it divided into the components and stays on the safe side, because surface temperatures influenced the drying potential of the surface significantly - higher temperature, higher evaporation and moisture transport.

\section{Conclusion}

This paper analyses the influence of the different boundary conditions created from the measured outdoor climate with short time step. The results showed that the measurement of diffuse solar radiation is very important if we want to obtain real outcomes. Without this component the software stays on the safe side and the outdoor surface temperature is similar to the air temperature.

Calculation in WUFI software showed that the use of a shorter time step is not usable at this time. The averaging of the actual values showed that there is possibility, that the average value will not represent the real course exactly. If there is a need to investigate some influences or to be on the safe side in some cases, maybe weighted average or maximal values will be suitable better. This will be analyzed in the future with comparison to the results from experimental wall measurement.

The research was done with the support of a grant project VEGA no. 1/0945/16.

\section{References}

1. M. Vertal, P. Durica, Moisture analyses of selected porous concrete materials suction curve, Civil and environmental engineering, no. 5, pp. 116-124 (2009)

2. P. Juras, P. Durica, Influence of wind-driven rain on the thermal conductivity of building envelopes with different cement-lime coatings, Communications: scientific letters of the University of Zilina, no. 4, pp. 74-80 (2016)

3. D. Staffenova et al., Climate Data Processing for Needs of Energy Analysis. $J$. Advanced Materials Research: enviBUILD vol. 1041 pp. 129-134 (2014) 
4. P. Juras et al., Full scale climate measurement around the building façade, Advanced Building Skins, Bern (2017)

5. D. Staffenova et al., Evaluative Case Study in Lightweight Wooden Wall Research, enviBuild conference, Vienna (2017)

6. P. Juras et al., Comparison of different windows for low-energy houses, RSP 2017 XXVI R-S-P Seminar Theoretical Foundation of Civil Engineering, vol. 117 (2017)

7. H. M. Kunzel, Simultaneous Heat and Moisture Transport in Building Components. One- and two-dimensional calculation using simple parameters, IBP Verlag, Stuttgart (1995) 